\title{
Article \\ Magnetic Properties of Nickel-Titanium Alloy during Martensitic Transformations under Plastic and Elastic Deformation
}

\author{
Ludmila I. Kveglis ${ }^{1,2, *}$, Fedor M. Noskov ${ }^{1}$, Mikhail N. Volochaev ${ }^{3}$, Alexander V. Nyavro ${ }^{4}$ \\ and Aleksander Filarowski $5,6, *$ (D) \\ 1 Polytechnical Institute of Siberian Federal University, Svobodny Ave. 79, 660041 Krasnoyarsk, Russia; \\ fnoskov@sfu-kras.ru \\ 2 Physics Department, Amanjolov East Kazakhstan University, 30th Guards Division Str. 34 \\ Ust-Kamenogorsk 070002, Kazakhstan \\ 3 Kirensky Institute of Physics, Siberian Division of Russian Academy of Science, Akademgorodok 50, \\ 660036 Krasnoyarsk, Russia; volochaev@iph.krasn.ru \\ 4 National Research, Tomsk State University, Lenin Ave. 36, 634050 Tomsk, Russia; nevr@phys.tsu.ru \\ 5 Faculty of Chemistry, University of Wrocław, 14 F. Joliot-Curie Str., 50-383 Wrocław, Poland \\ 6 Center for Advanced Research and Innovation, Industrial University of Tyumen, Volodarsky Str. 38, \\ 625000 Tyumen, Russia \\ * Correspondence: kveglis@iph.krasn.ru (L.I.K.); aleksander.filarowski@chem.uni.wroc.pl (A.F.); \\ Tel.: +7-960-7664152 (L.I.K.); +48-71-3757229 (A.F.)
}

Citation: Kveglis, L.I.; Noskov, F.M.; Volochaev, M.N.; Nyavro, A.V.; Filarowski, A. Magnetic Properties of Nickel-Titanium Alloy during Martensitic Transformations under Plastic and Elastic Deformation. Symmetry 2021, 13, 665. https:// doi.org/10.3390/sym13040665

Academic Editor: Enrico Bodo

Received: 17 March 2021

Accepted: 10 April 2021

Published: 13 April 2021

Publisher's Note: MDPI stays neutral with regard to jurisdictional claims in published maps and institutional affiliations.

Copyright: () 2021 by the authors. Licensee MDPI, Basel, Switzerland. This article is an open access article distributed under the terms and conditions of the Creative Commons Attribution (CC BY) license (https:// creativecommons.org/licenses/by/ $4.0 /)$.

\begin{abstract}
This paper focuses on the processes of the occurrence of magnetization during structure formation in samples of $\mathrm{Ni}_{51} \mathrm{Ti}_{49}$ alloy under deformation conditions. The possibility of the existence of a phase with an FCC (face-centered cubic) lattice in titanium nickelide has been demonstrated by electron microscopy and electron diffraction. It has been discovered that the interplanar distances of $\mathrm{BCC}_{110}$ (body-centered cubic), $\mathrm{FCC}_{111}$, and $\mathrm{HCP}_{002}$ (hexagonal close packed) in the alloy under study have similar values, which indicates the possibility of their mutual polymorphic transformation. Based on the modular self-organization, a scheme of martensitic transformations in titanium nickelide from the B2 structure (BCC lattice) to the B19' structure (HCP lattice) through an intermediate phase with an FCC lattice is proposed. It is shown that lenticular crystals appear in the $\mathrm{Ni}_{51} \mathrm{Ti}_{49}$ alloy under tensile deformation until rupture, which is accompanied by the onset of ferromagnetism. The effect of magnetization in $\mathrm{Ni}_{51} \mathrm{Ti}_{49}$ samples when immersed in liquid nitrogen has been also discovered. In this case, the reason for the appearance and disappearance of magnetization can be associated with microdeformation processes caused by direct and reverse martensitic transitions that occur during cooling and heating of the samples.
\end{abstract}

Keywords: titanium nickelide; deformation; martensitic transformation; electron diffraction; ferromagnetism; clusters

\section{Introduction}

A number of works is devoted to structural transformations in alloys based on titanium nickelide [1-16]. However, the published results regarding the structure and properties of these materials are contradictory. According to the established concepts, in binary alloys of titanium nickelide, the martensitic transformation occurs in two stages. Austenite with a cubic structure of type B2 passes into a phase with a trigonal rhombohedral R-structure. Then the R-structure passes into a phase with a monoclinic B19' structure [17].

The concept of mechanical twinning during load-initiated martensitic transformations is also well established $[7,18]$. The very fact of twinning in numerous planes with complex indices indicates the structural instability of the phases. The experimental detection of the deformation twins in the B2 phase of TiNi alloys cannot be described by sufficiently simple mechanisms [18]. 
The authors of papers $[19,20]$ discovered that the alloys that are macrohomogeneous in concentration and exhibit a phase transformation with a change in crystallographic modification (BCC-FCC, BCC-HCP, etc.) show the existence of microscopic regions with different directions of atomic displacements, the so-called microdomains. At such displacements, the crystal lattice of the initial phase locally loses its stability, and is characterized by the short-range order of atomic displacements. In [21], it is shown how, in the process of the martensitic transition, the angle between the basis vectors of the martensite phase changes with temperature. These facts show the structural instability during martensitic transformations.

In the general scheme of martensitic transformations, in the titanium nickelide alloys, the concept of the so-called premartensitic state is associated with the short-range order of atomic displacements $[19,20]$. According to $[19,20]$ at least two types of short-range order in the premartensitic state can arise in the B2 phase: one precedes the B19 phase, meanwhile another-the R-phase. Both these phases turn into the B19' phase. However, according to [22], martensitic transformations feature the absence of the incubation period of the transformation, which contradicts the concept of premartensitic phases. The concept of the appearance of the premartensitic state in the form of martensite nuclei is also proposed in [7]. The theory suggested in $[23,24]$ is the concept of cooperative thermal vibrations of extended two-dimensional objects (close-packed planes) in the titanium nickelide crystals. In accordance with this theory, atomic rearrangements in the process of BCC-FCC and BCC$\mathrm{HCP}$ transformations are combinations of shifts of close-packed planes of the BCC lattice.

Numerous concepts based on two-dimensional shifts in atomic networks during phase transformations encounter significant difficulties. In practice, the processes occurring during martensitic transitions turn out to be more complex than presented in the existing orientational schemes of martensitic transformations and require the involvement of other concepts (e.g., premartensitic states, cluster models of structure formation, or others).

The well-known Bane's model examines the martensitic transition in steels in three dimensions. However, Bane's model can be applied to a very limited range of cases. It is stated in ref. [22] that, even with the maximum carbon saturation of martensite in steel, the limiting ratio of the crystal lattice parameters does not exceed 1.08. This fact contradicts the Bane model [25], where the ratio is 1.41.

One of the actively developing concepts is the concept of cluster modeling of threedimensional structures. The essence of the method is that the polymorphic martensitic transformation is described not as a relative displacement of planar atomic networks, but as a reconstruction of three-dimensional coordination polyhedra that make up the crystal structures of the phase-partners in the phase transformation [26-29]. In [30,31], a cluster model of the formation of martensite from austenite in steel was proposed, where the polymorphic transformation in iron is performed by the formation of special twins in the FCC lattice and their "twinning" into the BCC structure. Moreover, a model of the crystal structure of the martensitic R-phase in the Ni-Ti system was proposed in [28,29], based on the concept of martensitic transformation as a reconstruction of the coordination polyhedra of the initial and final phases: the rhombododecahedron of the initial BCC structure transforms into the final cuboctahedron through the intermediate cluster configurations special phase and icosahedron. Notably, a cuboctahedron can be obtained from the crystal moduli of the FCC lattice.

There is the evidence that plastic deformation of the FCC lattice can lead to a transition to the rhombohedral phase and back to the phase with the FCC lattice. In [32], it was shown that during the plastic deformation of gold, along with the phase having the FCC lattice, a narrow band of the rhombohedral 9-R phase was found. The results of the calculations performed by the molecular dynamics method are in good agreement with the data of high-resolution electron microscopy.

In our previous work, we showed the possibility of forming titanium with the FCC lattice in thin-film samples [33]. Epitaxial titanium films were obtained by vacuum deposition of a $\mathrm{LiF}$ single crystal on a substrate at the temperature within $180-200^{\circ} \mathrm{C}$. The films with a 
thickness of up to $40 \mathrm{~nm}$ had a structure of the FCC lattice. With an increase in thickness to $70 \mathrm{~nm}$, a titanium phase with the HCP lattice appeared in the films. Both lattices were coherently coupled with the plane (111) FCC I I (0001) HCP, which corresponds to the Nishiyama ratios [26].

The possibility of the appearance of the FCC lattice in bulk samples of titanium nickelide after repeated cycles of forward and reverse martensitic transformations was presented [34]. The interpretation of the diffraction patterns revealed that the process of martensitic transformation of the B2 structure can proceed according to the KurdyumovSachs scheme [35]. We also investigated the magnetic states of deformed samples using a torsion magnetometer. The obtained data showed the appearance of magnetization in the $\mathrm{Ni}_{51} \mathrm{Ti}_{49}$ samples after repeated cycles of forward and reverse transformations [34]. A phase with non-zero bulk magnetization was formed in the samples during cyclic martensitic transformations. The ferromagnetic phase is distributed in the sample inhomogeneously.

The descriptions of the transformations in both works were completed using models of relative displacements of flat meshes. The challenging description of structural deformations during the martensitic transformation is associated with different designations of atomic planes and vectors of direct and reciprocal lattices for structures with different symmetry. Based on representing each structural state as a combination of elementary crystalline clusters, the method was proposed for modeling the cooperative motion of atoms in symmetric systems while preserving their connectivity [27].

There are data for individual intermetallic phases of the nickel-titanium system [36], where the calculation of the density of electronic states for the $\mathrm{Ni}_{4} \mathrm{Ti}_{3}$ phase is presented. The calculation of the density of electronic states at the Fermi level is high, which meets the Stoner criterion for the onset of magnetization. Obviously, the occurrence of magnetization can be caused by the phase formation during a mechanochemical reaction [37]. One of the hypotheses of the appearance of ferromagnetic properties in the $\mathrm{Ni}_{51} \mathrm{Ti}_{49}$ alloy after plastic deformation is associated with a decrease in the symmetry of the crystalline phase with a cubic lattice $[38,39]$. We assumed that the processes of the appearance of ferromagnetic properties resulting from repeated cycles of forward and reverse martensitic transitions in $\mathrm{Ni}-\mathrm{Ti}$ alloys can lead to the isolation of ferromagnetic particles rich in nickel $[40,41]$.

The following tasks were set in this paper: (1) to investigate the microstructure of thinned massive samples of $\mathrm{Ni}_{51} \mathrm{Ti}_{49}$ alloy subjected to tensile loading on a testing machine using the methods of electron microscopy and electron diffraction; (2) to investigate the occurrence of ferromagnetic properties in plastically deformed samples of $\mathrm{Ni}_{51} \mathrm{Ti}_{49}$ alloy by magnetometry methods; (3) to investigate the appearance of ferromagnetic properties in samples treated with liquid nitrogen for their elastic deformation caused by the passage of forward and reverse martensitic transitions; and (4) to construct models of the occurrence of martensitic transformations initiated by plastic and elastic deformation in titanium nickelide, from the standpoint of cluster self-organization.

\section{Materials and Methods}

The original rods of the $\mathrm{Ni}_{51} \mathrm{Ti}_{49}$ alloy were rolled in calibers at a temperature of $800^{\circ} \mathrm{C}$. Samples for mechanical tensile tests were cut out by the method of electric spark cutting in the form of double blades. Annealing and quenching of the samples to study changes in the structure were carried out in a chamber electric furnace. The samples were placed in an oven after preheating it. The samples were heated to an annealing temperature of $950{ }^{\circ} \mathrm{C} \pm 20^{\circ} \mathrm{C}$ with holding for one hour and cooling to room temperature in a furnace. The annealed samples were hardened from a temperature of $850{ }^{\circ} \mathrm{C}$ with preliminary holding in a furnace for an hour and held in water.

The samples after metallographic processing were subjected to static tension to rupture. Plastically deformed specimens in the neck area were thinned using the focused ion beam (FIB) installation. The microstructure was studied by transmission electron microscopy and microdiffraction on a Hitachi 7700 microscope. Next, the quenched samples of the $\mathrm{Ni}_{51} \mathrm{Ti}_{49}$ alloy were placed once in a cell with liquid nitrogen for 70-90 s. As a result of 
the passage of the martensitic transformation, the sample underwent elastic microstrains. After removing from the cuvette, the samples were placed into an induction loop scope to study the magnetic characteristics during heating to room temperature. The magnetic characteristics were evaluated on an induction loop scope designed to measure hysteresis loops for samples with magnetization from 20 Gauss minimum (including those from thin magnetic films). The facility was developed in the Kirensky Institute of Physics (Federal Research Center, Russian Academy of Sciences) [42].

To simulate the magnetic state of elastically and plastically deformed samples of the $\mathrm{Ni}_{51} \mathrm{Ti}_{49}$ alloy, a spin polarized calculation of the density of electronic states of intermediate phases was carried out by the method of scattered waves. Our calculations are based on the author's program, described in paper [43].

\section{Results}

Figure 1 shows an electron microscope image of the $\mathrm{Ni}_{51} \mathrm{Ti}_{49}$ sample stretched until rupture. A strong misorientation of slip bands is observed. This picture is typical for the microstructure of NiTi alloys subjected to strong tensile loads in the separation zone [41].

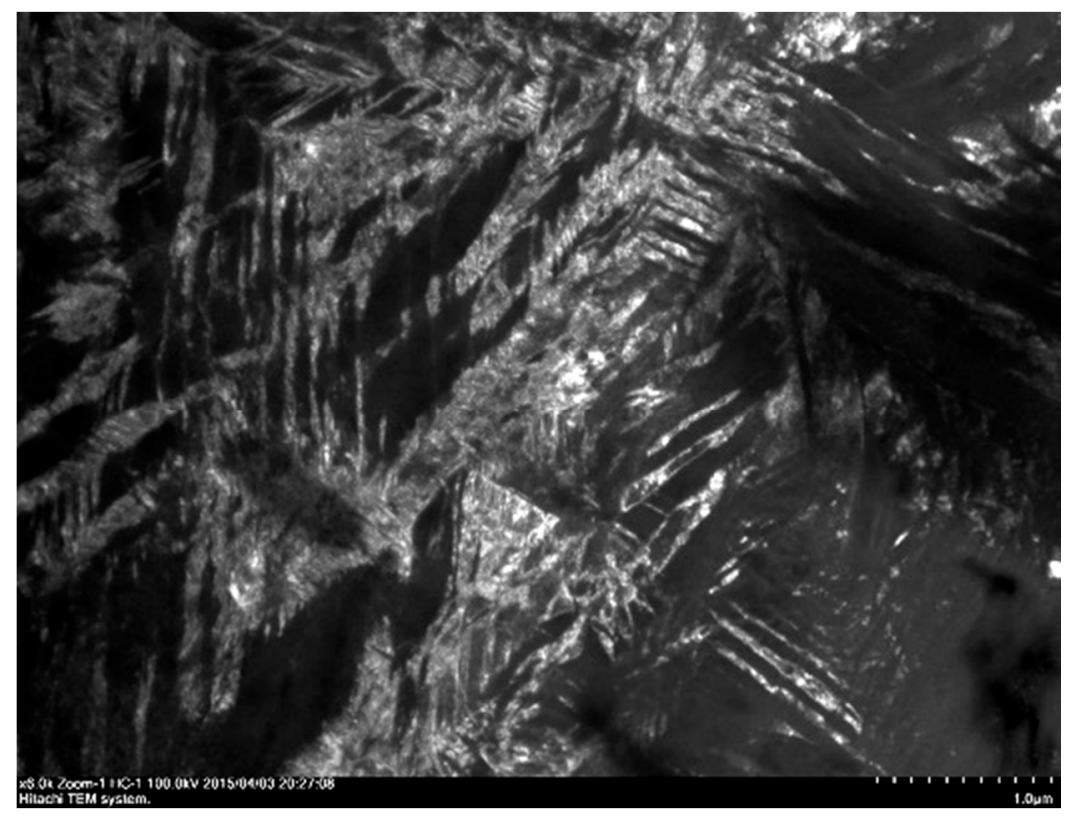

Figure 1. Electron microscopic image of the stretched $\mathrm{Ni}_{51} \mathrm{Ti}_{49}$ sample.

The electron diffraction pattern obtained from this area is shown in Figure 2a. The scheme for decoding the obtained diffraction pattern is shown in Figure $2 \mathrm{~b}$. The data are summarized in Table 1.

The interpretation of the diffraction pattern showed that in the sample, along with the phases with the B2 (BCC) and B19' (HCP) structures, reflections of the FCC phase were found (the lattice parameter was $a=4.20 \AA$ ). In addition to the main reflections of this phase, superstructural reflections are observed: $110^{*}, 3 / 23 / 20^{*}$ and $\frac{1}{2} \frac{1}{2} 0^{*}$. Along with the reflections of the BCC, FCC, and HCP NiTi phases, the reflections corresponding to strong lines of the $\mathrm{Ti}_{2} \mathrm{Ni}$ phase were detected (ASTM Card No. 18-0898) [44]. The column corresponding to $\mathrm{Ti}_{2} \mathrm{Ni}$ shows on the left, the Miller indexes, and on the right (in parentheses), the discrepancies in the interplanar distances in our experiment with tabular data, expressed in angstroms (Table 1).

The results of the measurements of the diffraction pattern obtained for a stretched sample of the $\mathrm{Ni}_{50,6} \mathrm{Ti}_{49,4}$ alloy (Figure 3) are seen in Table 2. The obtained experimental results are in accordance with those published in $[45,46]$. 


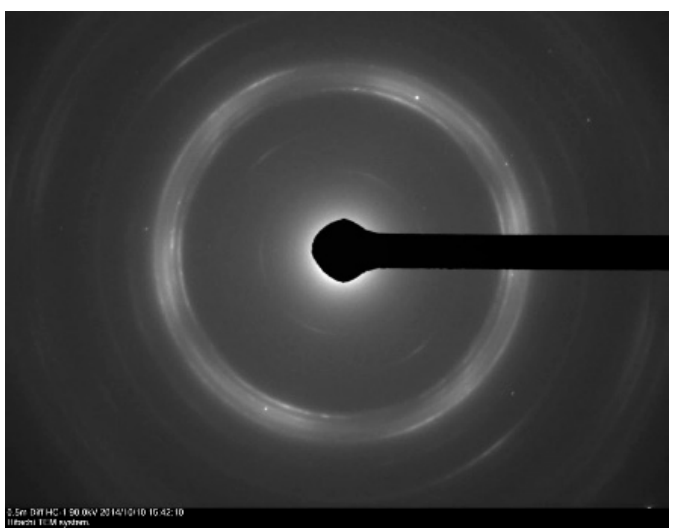

(a)

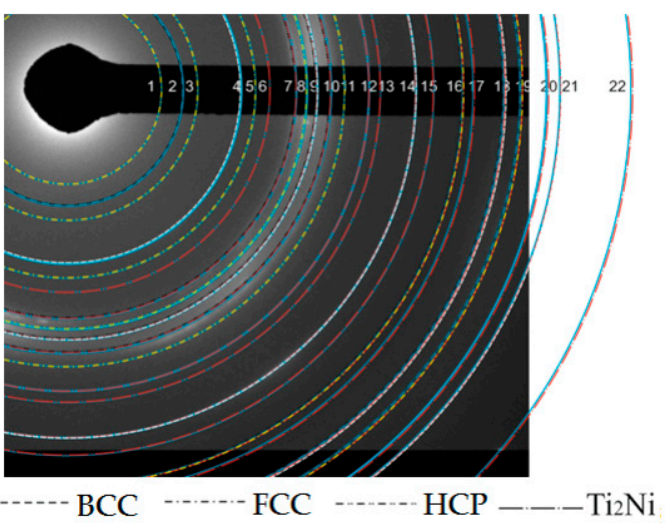

(b)

Figure 2. The electron diffraction pattern obtained from the area from the region of the stretched $\mathrm{Ni}_{51} \mathrm{Ti}_{49}$ sample (a). The scheme for decoding this picture $(\mathbf{b})$ is presented in Table 1.

Table 1. The results of decoding the diffraction pattern shown in Figure 2.

\begin{tabular}{|c|c|c|c|c|c|}
\hline Line Num. & $d, \AA$. & $\mathrm{BCC}, h k l$ & FCC,$h k l$ & $\mathrm{HCP}, h k l$ & $\begin{array}{c}\mathrm{Ti}_{2} \mathrm{Ni},[45] \\
h k l /(\Delta d, \AA)\end{array}$ \\
\hline 1 & 6.16 & & $\frac{1}{2} \frac{1}{2} 0^{*}$ & & \\
\hline 2 & 5.02 & & & $\frac{1}{2} 00^{*}$ & \\
\hline 3 & 4.45 & & $3 / 23 / 20^{*}$ & & \\
\hline 4 & 3.36 & $100^{*}$ & & & \\
\hline 5 & 3.09 & & $110^{*}$ & & \\
\hline 6 & 2.87 & & & & $400 /(-0.05)$ \\
\hline 7 & 2.54 & & & 100 & $331 /(+0.04)$ \\
\hline 8 & 2.43 & & 111 & & \\
\hline 9 & 2.33 & 110 & & 002 & $422 /(-0.03)$ \\
\hline 10 & 2.21 & & & 101 & $511 /(-0.04)$ \\
\hline 11 & 2.10 & & 200 & & \\
\hline 12 & 1.93 & & & & $531 /(-0.03)$ \\
\hline 13 & 1.86 & & & & $442 /(+0.02)$ \\
\hline 14 & 1.67 & 200 & & & $622 /(+0.03)$ \\
\hline 15 & 1.59 & & & & $551 /(-0.01)$ \\
\hline 16 & 1.47 & & 220 & 110 & $553 /(0.00)$ \\
\hline 17 & 1.43 & & & & $800 /(-0.02)$ \\
\hline 18 & 1.33 & 211 & & 103 & $660 /(0.00)$ \\
\hline 19 & 1.28 & & 311 & 200 & $662 /(+0.01)$ \\
\hline 20 & 1.21 & & & & $842 /(+0.02)$ \\
\hline 21 & 1.18 & 220 & & & $931 /(0.00)$ \\
\hline 22 & 1.03 & & & & $1111 /(-0.01)$ \\
\hline
\end{tabular}

The numbers in brackets show how much to add/subtract from our experimental data to the tabular indicator. Superstructural reflections are marked with asterisks.

The interpretation of the diffraction pattern (Figure 3 and Table 2) suggests that in the sample, along with the phases with the B2 (BCC) and B19' (HCP) structures, there may be reflections of the FCC phase with the lattice parameter $a=4.10 \AA$. These results are in agreement with those in our previous works $[33,34]$. In addition to the main reflections of the FCC phase, superstructural reflections are observed: $211^{*}$ and $\frac{1}{2} \frac{1}{2} \frac{1}{2} *$.

Along with the reflections of the $\mathrm{BCC}, \mathrm{FCC}$, and $\mathrm{HCP}$ phases, reflections corresponding to strong lines of the $\mathrm{Ni}_{4} \mathrm{Ti}_{3}$ phase were found (ASTM Card No. 39-1113). The column corresponding to $\mathrm{Ni}_{4} \mathrm{Ti}_{3}$ shows, on the left, Miller indexes, and on the right (in parentheses), discrepancies with the tabular data, expressed in angstroms.

Figure 4a shows the different types of hysteresis loops obtained before (1) and after (2) plastic deformation. 


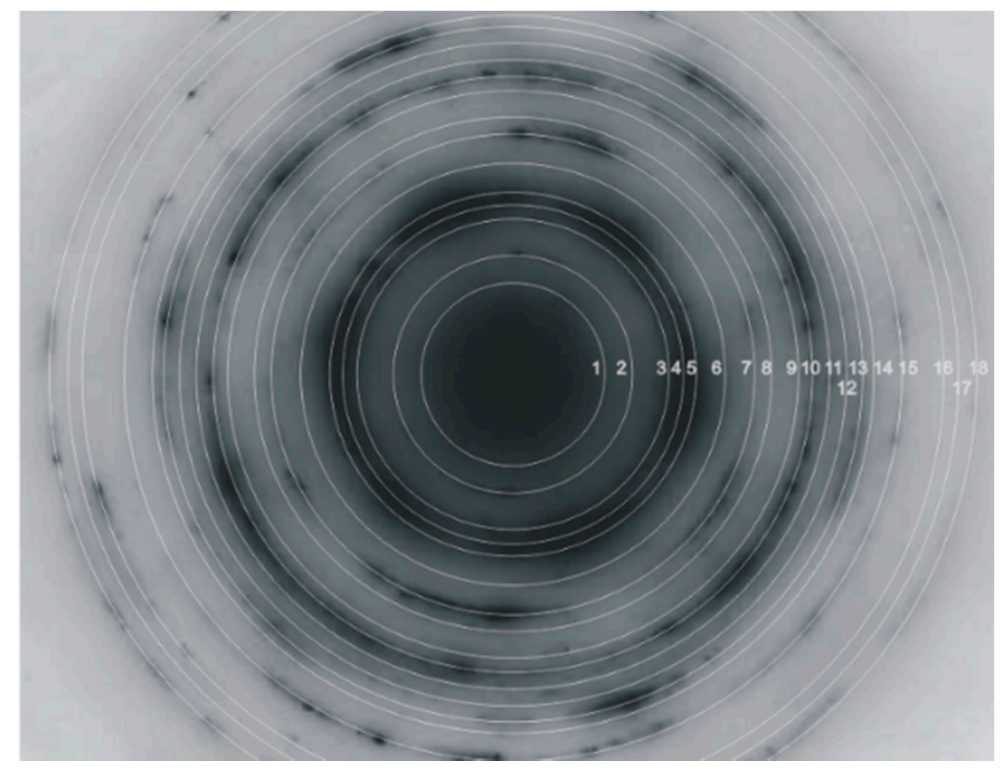

Figure 3. The electron diffraction pattern of the $\mathrm{Ni}_{50,6} \mathrm{Ti}_{49,4}$ alloy, coarse-grained after tension.

Table 2. The results of decoding the diffraction pattern shown in Figure 3.

\begin{tabular}{|c|c|c|c|c|c|}
\hline Line Num. & $d, \AA$. & $\mathrm{BCC}, \mathrm{Hkl}$ & $\mathrm{FCC}, h k l$ & $\mathrm{HCP}, h k l$ & $\begin{array}{c}\mathrm{Ni}_{4} \mathrm{Ti}_{3} \\
h k l /(\Delta d, \AA)\end{array}$ \\
\hline 1 & 4.70 & $\frac{1}{2} \frac{1}{2} 0^{*}$ & $\frac{1}{2} \frac{1}{2} \frac{1}{2} *$ & $001^{*}$ & \\
\hline 2 & 3.62 & & & & $3 / 2 \frac{1}{2} 2^{*}$ \\
\hline 3 & 2.78 & $1 \frac{1}{2} 0^{*}$ & & & \\
\hline 4 & 2.55 & & & 100 & \\
\hline 5 & 2.37 & 110 & 111 & 002 & $131 /(+0.01)$ \\
\hline 6 & 2.05 & & 200 & & $122 /(+0.04)$ \\
\hline 7 & 1.80 & & & & $312 /(+0.04)$ \\
\hline 8 & 1.69 & 200 & $211^{*}$ & 102 & $232 /(-0.02)$ \\
\hline 9 & 1.53 & $210^{*}$ & & & \\
\hline 10 & 1.46 & & 220 & & $422 /(+0.02)$ \\
\hline 11 & 1.38 & 211 & & & \\
\hline 12 & 1.31 & & & 103 & \\
\hline 13 & 1.25 & & 311 & 201 & \\
\hline 14 & 1.22 & 220 & 222 & 004 & $532 /(0.00)$ \\
\hline 15 & 1.13 & & & & \\
\hline 16 & 1.02 & 310 & 400 & & \\
\hline 17 & 0.99 & 222 & & & \\
\hline 18 & 0.95 & & 331 & & \\
\hline
\end{tabular}

The numbers in brackets show how much to add/subtract from our experimental data to the tabular indicator Superstructural reflections are marked with asterisks.

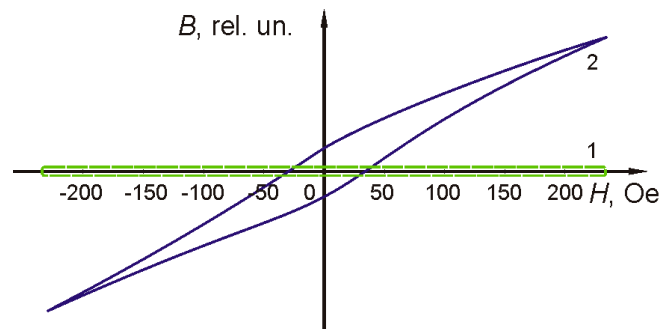

(a)

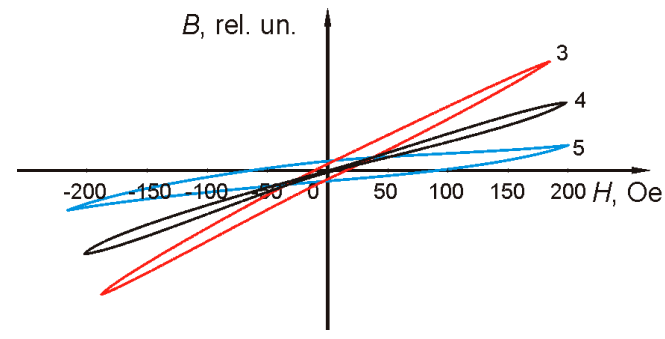

(b)

Figure 4. Hysteresis loops of $\mathrm{Ni}_{51} \mathrm{Ti}_{49}$ alloy: (a) before (1) and after (2) plastic deformation; (b) at various stages of heating from liquid nitrogen temperature to room temperature $(3,4$ and 5$)$. 
The appearance of magnetization was also observed as a result of a single immersion of an undeformed sample of titanium nickelide in liquid nitrogen. Figure $4 \mathrm{~b}$ depicts the changes in the hysteresis loops in time, when heating the sample from liquid nitrogen temperature to room temperature (3,4 and 5). It was observed that immediately after extraction from the liquid nitrogen, the sample gains magnetization, which decreases as it is heated to room temperature, so that at room temperature the magnetic properties disappear.

Numerous features of martensitic transformations in the Ni-Ti alloys (such as transformation temperatures, presence and amount of intermediate phases, nature and mechanism of martensitic transformation) largely depend on the presence of lenticular nanocrystals of the $\mathrm{Ni}_{4} \mathrm{Ti}_{3}$ phase [36]. Studies [47] have shown the appearance of lenticular single crystals under the impact of an electron beam in amorphous metal films and metal compounds. After plastic deformation, lenticular crystals containing bend contours with a high concentration of internal stresses were found in $\mathrm{Ni}_{51} \mathrm{Ti}_{49}$ samples. A TEM image of a crystal is shown in Figure 5.

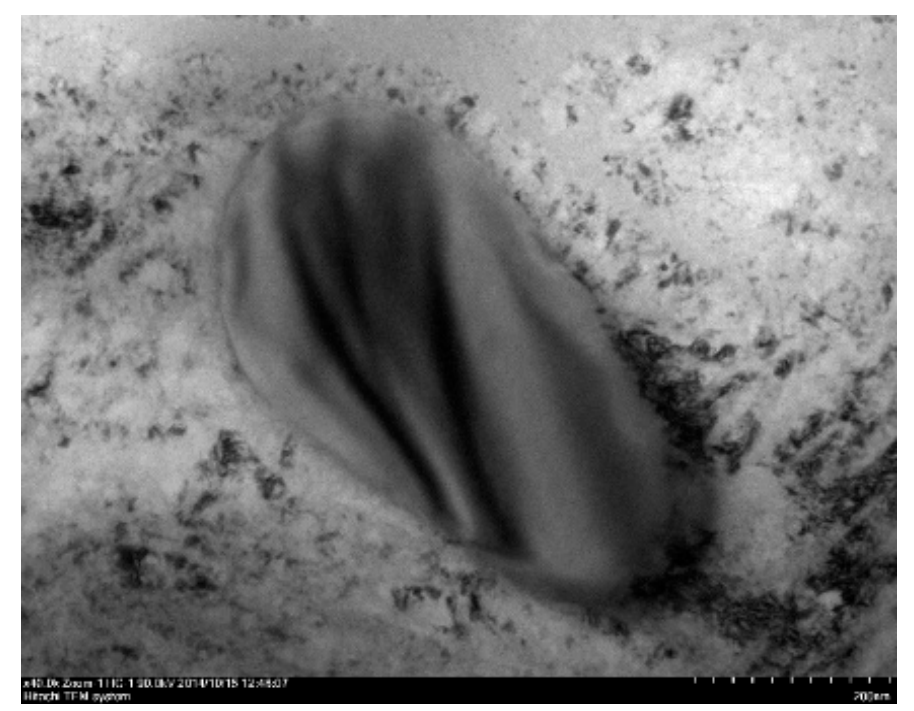

Figure 5. TEM image of a lenticular crystal containing bend contours with a high concentration of internal stresses.

\section{Discussion}

There are known cases in the literature $[19,20]$ where transitions from the phase with the B2 structure to the phase with the B19' structure through an intermediate structure with a rhombohedral lattice are described. The data on the structure of the rhombohedral phase are ambiguous and contradictory [6-10].

Based on the analysis of the diffraction patterns obtained in this work, as well as in our previous works $[33,34]$ and in [47], we propose a hypothesis that the transition from the B2 phase to the B19' phase can occur through an intermediate FCC phase. This hypothesis rests upon the fact that the interplanar distances of $\mathrm{BCC}_{110}, \mathrm{GPU}_{002}$, and $\mathrm{FCC}_{111}$ are very close (Tables 1 and 2). This fact speaks in favor of the model of modular self-organization during phase transformations from the phase with the BCC lattice to the phase with the HCP lattice.

Pearson [26] describes the structure of the BCC lattice as a system consisting of six irregular octahedra (Figure 6a). Such an octahedron has a height equal to the edge of the cube of the BCC lattice $a$, and the other two heights are equal to $a \times \sqrt{ } 2$. Six irregular octahedra make up a dodecahedron with twelve diamond-shaped faces (rhombic dodecahedron). One height of the rhombus is equal to the edge of the cube of the BCC lattice $a$, and the other is equal to $a \times \sqrt{ } 2$. Thus, the described irregular octahedron can be represented as an elementary cluster of the BCC lattice. 


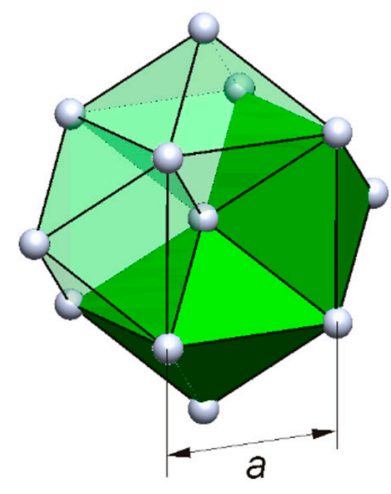

(a)

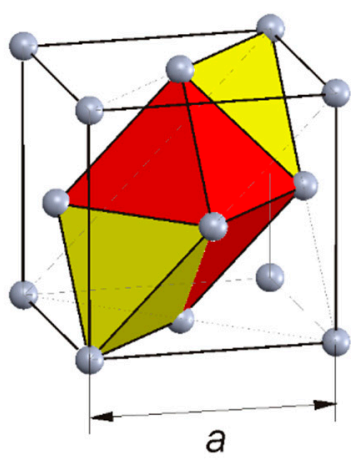

(b)

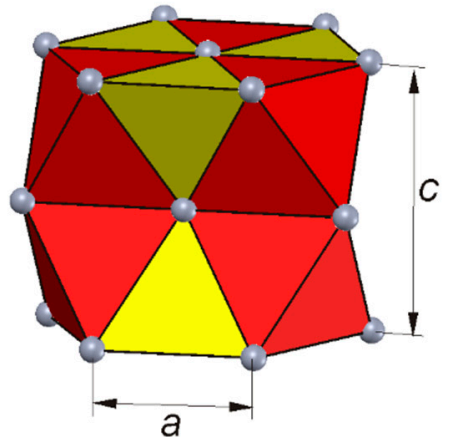

(c)

Figure 6. Modular representation of crystal structures with: (a) BCC lattice [26]; (b) FCC lattice [27]; (c) hexagonal close-packed (HCP) lattice [26,27].

According to [27], the FCC lattice can be represented as a combination of one regular octahedron surrounded by regular tetrahedra connected by common triangular planes (Figure 6b). A hexagonal close-packed (HCP) lattice can be represented as a combination of interconnected pairs of regular octahedra, alternating with pairs of regular tetrahedra (Figure 6c). Thus, the elementary clusters of both FCC and HCP lattices are the regular octahedron (all of whose heights are equal to the edge of the cube $a$, and the edges are equal to $a / \sqrt{ } 2$ ) and the regular tetrahedron (all the heights of which are equal to $a / \sqrt{ } 3$ and the edges are equal to $a / \sqrt{ } 2$, respectively) [27]. The difference between the FCC and $\mathrm{HCP}$ lattices lies in the arrangement of the tetrahedra and octahedra. Thus, the interplanar spacing $d_{002}$ of the HCP lattice is equal to $d_{111}$ of the FCC lattice, i.e., in places of stress localization, one lattice can easily pass into another as a result of minor displacements of individual atoms. The maximum value of such displacements is $a / \sqrt{ } 6$.

Notably, the density of atoms in the FCC and HCP lattices is the same and amounts to 0.74. The grid model of crystal structures assumes the arrangement of triangular networks in the FCC lattice according to the ABCABS system, and in the HCP lattice according to the ABABAB system. Thus, in order to pass from an FCC lattice to an HCP lattice, it is sufficient to move one flat triangular grid $C$ from the $A B C$ series by $a / \sqrt{ } 6$. However, in reality, such an operation is impossible, while the displacement of individual atoms under the influence of plastic deformation is quite probable.

There are many examples of transitions from HCP to FCC that happen due to an increase in the temperature [27]. The transition from BCC to HCP is explained ambiguously $[6-10,17-21,28,29]$. In our opinion, if a crystal with the BCC lattice is subjected to an external load, then in the zone of stress localization, the atoms of the BCC lattice can be displaced by a distance equal to $0.15 \times a$ of the FCC lattice (this distance is shown by up and down arrows in Figure 7).

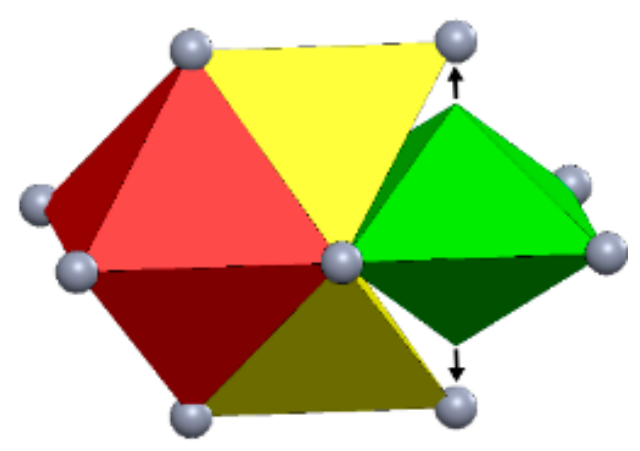

Figure 7. Formation of the FCC lattice from an octahedral cluster of the BCC lattice (arrows indicate the displacement of BCC atoms to the position of FCC atoms). 
At high levels of stress, the lengths of all interatomic bonds tend to "align", which is easy to associate with the repulsive energy, usually described by potentials $B / \mathrm{r}^{\mathrm{n}}$, where $r$ is the interatomic distance, $n$ is a natural series of numbers, and $B$ is a constant [48]. The author showed that repulsion in symmetric structures, such as clusters of the FCC lattice, plays a much smaller role. At large deformations, when the energy of the system is determined mainly by repulsive forces, the most stable structures are those in which all bonds have approximately the same length [48]. Thus, in the regions of stress localization, a transition from asymmetric clusters of the BCC lattice to symmetric clusters of the FCC lattice can occur, as shown in Figure 7. In turn, clusters of the FCC lattice can transform into clusters of the HCP lattice due to further displacement of individual atoms in localized regions.

According to the theory [40], in the zones of local tension, an increased molar volume is created (in our case, relative to the BCC phase), in which a local structural transformation can occur. The action of the stresses moment in these zones creates a local curvature of the crystal lattice, which is clearly demonstrated in Figure 5 and in the appearance in the curvature zone of a highly excited nonequilibrium state of the material. In the curvature zone, new structural states of the short-range order of displacements appear, which have their own band of energy states in the electron-energy spectrum [40], hence, the displacements of atoms considered above during cluster transformations (for example, by $a / \sqrt{ } 6$ or $0.15 \times a$ of the FCC lattice) are possible and apparently have limiting values. In practice, significantly smaller displacement values are realized. So, we observe a shift of the $\mathrm{FCC}_{111}$ peak (line 8 ) relative to the $\mathrm{BCC}_{110}$ and $\mathrm{HCP}_{002}$ lines (line 9) by $0.1 \AA$ (Table 1 ). The possibility of atomic displacement during martensitic transitions was experimentally shown in [49], where iron atoms can be displaced from their positions by up to $0.2 \AA$.

The analysis of Table 1 states that the displacement of atoms in individual zones under inhomogeneous loads does not exceed $0.15 \AA$. For example, the $\mathrm{BCC}_{200}$ reflex is $1.67 \AA$ (Table 1 ), and the $\mathrm{BCC}_{100}$ reflex, which in equilibrium conditions should be $1.67 \times 2=3.34 \AA$, and in our case is $3.36 \AA$. The shift of the lines of the diffraction pattern in crystals undergoing curvature has been sufficiently well studied in the work of Kolosov [47]. The curved crystals are seen in the electron microscopic image (Figure 1). The distortion of the crystal lattices can explain the discrepancy between the interplanar distances $d$ of the corresponding reflections when comparing Tables 1 and 2.

There is an opinion that in a wide temperature range, the single-phase region of the NiTi compound does not exist, but decomposition into a mixture of two phases $\mathrm{Ti}_{2} \mathrm{Ni}+\mathrm{Ti}_{4} \mathrm{Ni}_{3}$ occurs $[50,51]$. This can explain the appearance of reflections of the $\mathrm{Ti}_{2} \mathrm{Ni}$ and $\mathrm{Ni}_{4} \mathrm{Ti}_{3}$ phases in the diffraction patterns. The possibility of coexistence of these phases as partners was shown in $[52,53]$. The deviation in the interplanar distances of the revealed phases relative to the tabular values (see the data in parentheses in the last columns of Tables 1 and 2) can also be explained by the curvature of the crystal lattices of these phases.

In lenticular crystals, bending contours are observed (Figure 5), which indicate the curvature of the crystal lattice as a result of irreversible displacement of atoms. In this case, the transformation of the initial BCC lattice into the FCC lattice takes place. The FCC lattice contains clusters: octahedra and tetrahedra. The shift and rotation of octahedra and tetrahedra can lead to the formation of hexagonal and other types of lattices. According to [54], octahedra can be transformed into tetrahedra by just switching only one chemical bond of octahedron. As a result, tetrahedrally close-packed clusters in the form of endless spirals are built up. In Figure 8, the cluster corresponding to the $\mathrm{Ni}_{4} \mathrm{Ti}_{3}$ phase is shown, where the chemical bonds are practically equivalent. Such a structure can be a product of a mechanochemical reaction, since the octahedral clusters transform into the tetrahedral ones, while the local volume per atom decreases significantly, which corresponds to the metastable state of this phase. This leads to an increase in the density of electronic states at the Fermi level and, accordingly, the appearance of magnetization. 


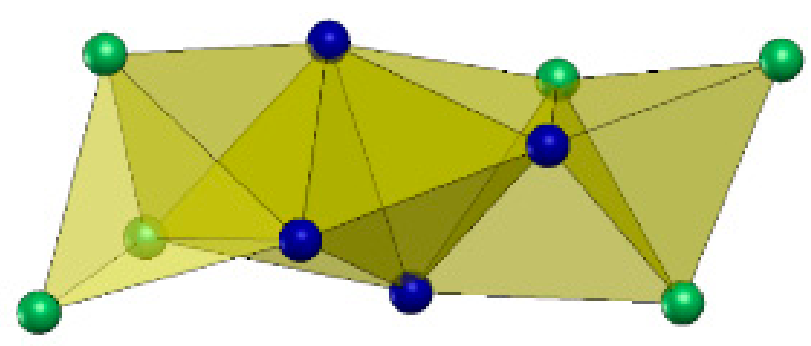

Figure 8. Tetrahedrally compacted cluster simulating the metastable state of the Ni4Ti3 structure: the central tetrahedron (blue balls) illustrates the positions of four nickel atoms, and green balls show the positions of titanium atoms. Articulating with each other, these elements form an endless spiral.

When a metal sample is cooled to the temperature of liquid nitrogen, microplastic and elastic deformations appear in it, caused by direct and reverse martensitic transformations [55]. The emergence and disappearance of magnetization in the $\mathrm{Ni}_{51} \mathrm{Ti}_{49}$ alloy samples revealed in these studies are associated with atomic displacements occurring during cooling and heating of the alloy during its treatment with liquid nitrogen.

In order to explain the possibility of the appearance of magnetization in the samples of the Ni-Ti alloy, we calculated the spin-polarized density of electronic states and magnetic moments of tetrahedrally compacted clusters of the type demonstrated in Figure 8, which shows alloy $\mathrm{Ni}_{51} \mathrm{Ti}_{49}$ electrons with different projection of spins: "up" and "down". The calculation was carried out by the scattered wave method [56,57]. To construct the "muffin-tin" potential of clusters, the electron densities were calculated using the unrestricted Hartree-Fock method [58-60] with the Gunnarson-Lundqvist exchange correlation potential [61]. This potential makes it possible to effectively describe the magnetic states of both atoms and the entire cluster as a whole [43].

Figure 9 shows the calculations of the spin densities of electronic states for tetrahedrally close-packed clusters, both for the undeformed (with the same bond length) and for the deformed cluster (the lengths of individual bonds are shortened), respectively.

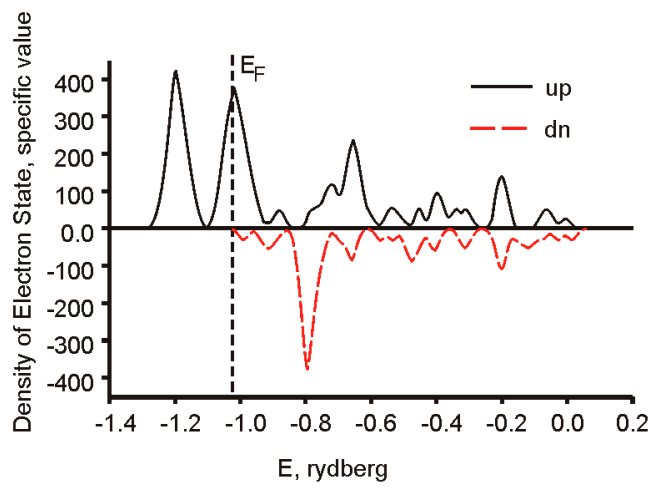

(a)

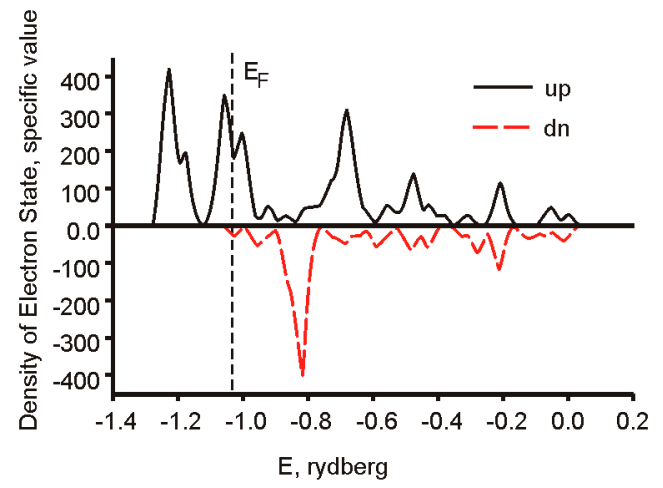

(b)

Figure 9. Distribution of the electron density for tetrahedrally densely packed clusters N(E): (a) the deformed cluster and (b) the undeformed cluster. The solid line corresponds to the density of electrons with spin "up" $(\uparrow)$, the dashed line, and with spin “down" $(\downarrow) . E_{F}$ is the position of the Fermi level.

The spectra in Figure 9 present a high density near the Fermi level, which is a characteristic feature of ferromagnetic metals. There is a difference between the spin polarized density of electronic states for the undeformed and deformed clusters. An increase in the magnetization of the alloy was recorded during spin-polarized calculations for deformed clusters. It is shown that the clusters under study also have a magnetic moment (the 
average magnetic moment per atom of the undeformed cluster is about $0.3 \mu \mathrm{B}$, and for the deformed one, it is about $1.0 \mu \mathrm{B}$ ).

\section{Conclusions}

The microstructure of the thinned $\mathrm{Ni}_{51} \mathrm{Ti}_{49}$ alloy specimens subjected to tensile load has been studied by electron microscopy and electron diffraction. The possibility of a phase with the FCC lattice in titanium nickelide was shown. It was discovered that the interplanar distances of $\mathrm{BCC}_{110}, \mathrm{FCC}_{111}$, and $\mathrm{HCP}_{002}$ in the studied alloy have similar values, which indicates the possibility of their mutual polymorphic transformation. The scheme of martensitic transformations in titanium nickelide from the B2 structure (BCC lattice) to the $\mathrm{B} 19^{\prime}$ structure (HCP lattice) through an intermediate phase with an FCC lattice based on self-organization is suggested. During the experiment, the appearance of magnetization in the plastically deformed $\mathrm{Ni}_{51} \mathrm{Ti}_{49}$ alloy was found. This magnetization is explained by the appearance of the tetrahedrally densely packed clusters in the zones of curvature of the crystal lattice. The appearance and disappearance of magnetization in the samples of the $\mathrm{Ni}_{51} \mathrm{Ti}_{49}$ alloy treated with liquid nitrogen is associated with reversible displacements of atoms during the forward and reverse martensitic transitions.

Author Contributions: Conceptualization, L.I.K. and F.M.N.; methodology, L.I.K. and M.N.V.; software, A.V.N.; validation, L.I.K., M.N.V. and A.V.N.; formal analysis, L.I.K.; investigation, L.I.K. and M.N.V.; resources, L.I.K. and F.M.N.; data curation, L.I.K. and A.V.N.; writing-original draft preparation, L.I.K. and F.M.N.; writing-review and editing, L.I.K., F.M.N. and A.F.; visualization, F.M.N.; supervision, L.I.K.; project administration, L.I.K.; funding acquisition, A.F. All authors have read and agreed to the published version of the manuscript.

Funding: This research received no external funding.

Institutional Review Board Statement: Not applicable.

Informed Consent Statement: Informed consent was obtained from all subjects involved in the study.

Data Availability Statement: Not applicable.

Conflicts of Interest: The authors declare no conflict of interest.

\section{References}

1. Otsuka, K.; Wayman, C.M. Shape Memory Materials; Cambridge University Press: Cambridge, UK, 1999.

2. Lagoudas, D.C. Shape Memory Alloys: Modeling and Engineering Applications; Springer: Berlin, Germany, 2008.

3. Yamauchi, K.; Ohkata, I.; Tsuchiya, K.; Miyazaki, S. Shape Memory and Superelastic Alloys: Applications and Technologies; Woodhead Publishing: Cambridge, UK, 2011.

4. Likhachev, V.A.; Kuz'min, S.L.; Kamentsova, Z.P. Effect Shape Memory; Leningrad State University: Leningrad, Russia, 1987.

5. Pogrebnjak, A.D.; Bratushka, S.N.; Beresnev, V.M.; Levintant-Zayonts, N. Shape memory effect and superelasticity of titanium nickelide alloys implanted with high ion doses. Rus. Chem. Rev. 2013, 82, 1135-1159. [CrossRef]

6. Buehler, W.J.; Gilfrich, J.V.; Wiley, R.C. Effect of low-temperature phase changes on the mechanical properties of alloys near composition TiNi. J. Appl. Phys. 1963, 34, 1475-1477. [CrossRef]

7. Malygin, G.A. Diffuse martensitic transitions and the plasticity of crystals with a shape memory effect. Usp. Fiz. Nauk 2001, 171, 187-212. [CrossRef]

8. Potekaev, A.I.; Glezer, A.M.; Kulagin, V.V.; Starostenkov, M.D.; Klopotov, A.A. Structure and Properties of Intermetallics in PreTransitional Low-Stability States; CRC Press, Taylor Francis Group: Boca Raton, FL, USA; London, UK; New York, NY, USA, 2020.

9. Otsuka, K.; Ren, X. Physical metallurgy of Ti-Ni-based shape memory alloys. Prog. Mat. Sci. 2005, 50, 511-678. [CrossRef]

10. Fadlallah, A.S.; El-Bagoury, N.; Gad, E.-R.M.S.; Ahmed, A.R.; El-Ousamii, G. An overview of NiTi shape memory alloy: Corrosion resistance and antibacterial inhibition for dental application. J. Alloys Compd. 2014, 583, 455-464. [CrossRef]

11. Shabalovskaya, A.S. On the nature of the biocompatibility and on medical applications of NiTi shape memory and superelastic alloys. Biomed. Mater. Eng. 1996, 6, 267-289. [CrossRef] [PubMed]

12. Khoo, Z.X.; Liu, Y.; An, J.; Chua, C.K.; Shen, Y.F.; Kuo, C.N. A review of selective laser melted NiTi shape memory alloy. Materials 2018, 11, 519. [CrossRef]

13. Rupérez, E.; Manero, J.M.; Bravo-González, L.-A.; Espinar, E.; Gil, F.J. Development of biomimetic NiTi Alloy: Influence of thermo-chemical treatment on the physical, mechanical and biological behavior. Materials 2016, 9, 402. [CrossRef]

14. Cayron, C. What EBSD and TKD tell us about the crystallography of the martensitic B2-B19' transformation in NiTi shape memory alloys. Crystals 2020, 10, 562. [CrossRef] 
15. Wang, M.; Jiang, S.; Zhang, Y. Phase transformation, twinning, and detwinning of NiTi shape-memory alloy subject to a shock wave based on molecular-dynamics simulation. Materials 2018, 11, 2334. [CrossRef]

16. Chang, S.-H.; Lin, K.-H.; Wu, S.-K. Effects of cold-rolling/aging treatments on the shape memory properties of Ti49.3Ni50.7 shape memory alloy. Materials 2017, 10, 704. [CrossRef]

17. Fan, G.; Zhoua, Y.; Chena, W.; Yanga, S.; Rena, X.; Otsuka, K. Precipitation kinetics of $\mathrm{Ti}_{3} \mathrm{Ni}_{4}$ in polycrystalline Ni-rich TiNi alloys and its relation to abnormal multi-stage transformation behavior. Mater. Sci. Eng. A 2006, 438-440, 622-626. [CrossRef]

18. Tyumentsev, A.N.; Surikova, N.S.; Lysenko, O.V.; Litovchenko, I.Y. Regularities and mechanisms of mechanical twinning in alloys based on titanium nickelide. Phys. Mesomech. 2007, 10, 53-66. [CrossRef]

19. Zolotukhin, Y.S.; Lotkov, A.I.; Klopotov, A.A.; Grishkov, V.N. Structure of domains formed upon martensitic transformations B2 $\rightarrow$ B19 and B2 $\rightarrow$ B19' in alloys with a B2 superstructure. Phys. Met. Metallogr. 2011, 111, 431-440. [CrossRef]

20. Zolotukin, Y.S.; Lotkov, A.I.; Klopotov, A.A.; Grishkov, V.N. Symmetry of pretransition structures in alloys with a B2-type superstructure. Phys. Met. Metallogr. 2012, 113, 438-447. [CrossRef]

21. Sitepul, H.; Schmahll, W.W.; Stalick, J.K. Correction of intensities for preferred orientation in neutron-diffraction data of NiTi shape-memory alloy using the generalized spherical-harmonic description. Appl. Phys. A 2002, 74, S1719-S1721. [CrossRef]

22. Biront, V.S. Theory of Thermal Processing of Metals. Hardening, Aging and Tempering; GATsMiZ: Krasnoyarsk, Russia, 1998.

23. Kassan-Ogly, F.A.; Naish, V.E.; Sagaradze, I.V. Diffuse scattering in metals with a BCC lattice and crystal geometry of martensitic phase transitions BCC-FCC and BCC-HCP. Phys. Met. Metallogr. 1988, 65, 481-492.

24. Lekston, Z.; Naish, V.E.; Novoselova, T.V.; Sagaradze, I.V. Structure and symmetry of the trigonal R-phase of titanium nickelide. Phys. Met. Metallogr. 1999, 87, 5-12.

25. Lobodyuk, V.A.; Koval', Y.N.; Pushin, V.G. Crystal-structural features of pretransition phenomena and thermoelastic martensitic transformations in alloys of nonferrous metals. Phys. Met. Metallogr. 2011, 111, 165-189. [CrossRef]

26. Pearson, W.B. The Crystal Chemistry and Physics of Metals and Alloys; Wiley-Interscience: New York, NY, USA, 1972.

27. Bulienkov, N.A.; Tytik, D.L. Modular design of icosahedral metal clusters. Russ. Bull. Chem. 2001, 50, 1-19. [CrossRef]

28. Kraposhin, V.S.; Talis, A.L.; Lam, H.T.; Dubois, J.-M. Model for the transformation of anicosahedral phase into a B2 crystallinephase. J. Phys. Condens. Matter. 2008, 20, 235215. [CrossRef]

29. Kablov, D.E.; Kraposhin, V.S.; Talis, A.L. Crystallographic mechanism of local lattice turn under growth of single crystals of refractory nickel alloys. Met. Sci. Heat Treat. 2017, 58, 712-718. [CrossRef]

30. Kraposhin, V.; Schastlivtsev, V.; Jakovleva, I.; Talis, A. New model for carbon distribution in austenite and steel transformation products. Mater. Today Proc. 2015, 2, S557-S560. [CrossRef]

31. Kraposhin, V.S.; Jakovleva, I.L.; Karkina, L.E.; Nuzhny, G.A.; Zubkova, T.A.; Talis, A.L. Microtwinning as a common mechanism for the martensitic and pearlitic transformations. J. Alloys Compd. 2013, 577S, 30-36. [CrossRef]

32. Kuznetsov, A.R.; Gornostyrev, Y.N. Structural Transformations at Grain Boundaries. Phase and Structural Transformations in Steels; Magnitogorsk State Technical University: Magnitogorsk, Russia, 2003.

33. Pynko, V.G.; Kveglis, L.I.; Korchmar, V.S. Epitaxial growth of Ti, V, Cr, V films on LiF and NaCl. Sov. Phys. Solid State 1971, 13, 3334-3337.

34. Abylkalykova, R.B.; Tazhibaeva, G.B.; Noskov, F.M.; Kveglis, L.I. The features of the martensitic transformation in Titanium Nickelide. Bull. Russ. Acad. Sci. Phys. 2009, 73, 1542-1544. [CrossRef]

35. Kurdjumow, G.; Sachs, G. Über den mechanismus der stahlhärtung. Z. Physik 1930, 64, 325-343. [CrossRef]

36. Kulkova, S.E.; Valujsky, D.V.; Smolin, I.Y. Changes in the electronic structure upon the B2-B19' martensitic transformation in titanium-nickel. Phys. Solid State 2001, 43, 737-745. [CrossRef]

37. Takacs, L. Mechanochemistry and the other branches of chemistry: Similarities and dierences. Acta Phys. Pol. A 2012, 121, 711-714. [CrossRef]

38. Khomskii, D.I.; Kugel, K.I.; Sboychakov, A.O.; Streltsov, S.V. Role of local geometry in the spin and orbital structure of transition metal compounds. J. Exp. Theor. Phys. 2016, 122, 484-498. [CrossRef]

39. Goodenough, J.B. Magnetism and the Chemical Bond; Wiley Interscience: New York, NY, USA, 1963.

40. Panin, V.E.; Egorushkin, V.E. Curvature solitons as generalized structural wave carriers of plastic deformation and fracture. Phys. Mesomech. 2013, 16, 267-286. [CrossRef]

41. Panin, V.E.; Egorushkin, V.E. Fundamental role of local curvature of crystal structure in plastic deformation and fracture of solids. AIP Conf. Proc. 2014, 1623, 475-478.

42. Zhigalov, V.S. Methods of Obtaining Magnetic Layers and Studies of Their Physical Properties: Textbook; SibGAU: Krasnoyarsk, Russia, 2008.

43. Nyavro, A.V. Evolution of Electronic States: Atom-Molecule-Cluster-Crystal; Publishing House of Tomsk State University: Tomsk, Russia, 2013.

44. Dudarev, E.F.; Valiev, R.Z.; Kolobov, Y.R.; Lotkov, A.I.; Pushin, V.G.; Bakash, G.P.; Gunderov, D.V.; Dyupin, A.P.; Kuranova, N.N. On the nature of anomalously high plasticity of high-strength titanium nickelide alloys with shape memory effects: II. Mechanisms of plastic deformation upon isothermal loading. Phys. Met. Metallogr. 2009, 107, 298-311. [CrossRef]

45. Yurko, G.A.; Barton, J.W.; Parr, J.G. The crystal structure of Ti ${ }_{2}$ Ni. Acta Cryst. 1959, 12, 909-911. [CrossRef]

46. Yurko, G.A.; Barton, J.W.; Parr, J.G. The crystal structure of Ti ${ }_{2}$ Ni. (A correction). Acta Cryst. 1962, 15, 1309. [CrossRef] 
47. Kolosov, V.Y.; Tholen, A.R. Transmission electron microscopy studies of the specific structure of crystals formed by phase transition in iron oxide amorphous films. Acta Mater. 2000, 48, 1829-1840. [CrossRef]

48. Burdett, J.K. Chemical Bonding in Solids; Oxford University Press: Oxford, UK, 1995.

49. Lipson, H.; Parker, A.M.B. Structure of martensite. J. Iron Steel Inst. 1944, 149, 123-141.

50. Surikova, N.S.; Klopotov, A.A.; Korznikova, E.A. Mechanisms of plastic deformation in microcrystalline and nanocrystalline TiNi-based alloys. Phys. Met. Metallogr. 2010, 110, 269-278. [CrossRef]

51. Klopotov, A.A.; Yasenchuk, Y.F.; Abzaev, Y.A.; Dement'eva, M.G.; Kozlov, E.V.; Potekaev, A.I.; Solonitsyna, N.O. System Ni-Ti. Crystallogeometrical features. Russ. Phys. J. 2008, 51, 226-239. [CrossRef]

52. Talis, A.; Kraposhin, V. Finite noncrystallographic groups, 11-vertex equi-edged triangulated clusters and polymorphic transformations in metals. Acta Cryst. 2014, A70, 616-625. [CrossRef]

53. Kuraposhin, V.S.; Talis, A.L.; Demina, E.D.; Zaitsev, A.I. Crystal geometry mechanism of intergrowth of spinel and manganese sulfide into a complex nonmetallic inclusion. Met. Sci. Heat Treat. 2015, 57, 371-378. [CrossRef]

54. Lipscomb, W.N. Framework rearrangement in boranes and carboranes. Science 1966, 153, 373-378. [CrossRef] [PubMed]

55. Razorenov, S.V.; Garkushin, G.V.; Kanel, G.I.; Kashin, O.A.; Ratochka, I.V. Behavior of nickel-titanium shape memory alloys under shock-wave loading. Phys. Solid State 2011, 53, 768-773. [CrossRef]

56. Slater, J.C.; Johnson, K.H. Self-consistent field $\mathrm{X}_{\alpha}$ cluster method for polyatomic molecules and solids. Phys. Rev. B 1972, 5, 844-853. [CrossRef]

57. Slater, J.C. Suggestions from solid-state theory regarding molecular calculations. J. Chem. Phys. 1965, 43, S228. [CrossRef]

58. Hartree, D.R. The wave mechanics of an atom with a non-coulomb central field. Part I. Theory and methods. Math. Proc. Camb. Philos. Soc. 1928, 24, 89-110. [CrossRef]

59. Hartree, D.R. The wave mechanics of an atom with a non-coulomb central field. Part II. Some results and discussion. Math. Proc. Camb. Philos. Soc. 1928, 24, 111-132. [CrossRef]

60. Fock, V.A. Näherungsmethode zur Lösung des quantenmechanischen Mehrkörperproblems. Z. Phys. 1930, 61, 126-148. [CrossRef]

61. Gunnarsson, O.; Lundqvist, B.I.; Wilkins, J.W. Contribution to the cohesive energy of simple metals: Spin-dependent effect. Phys. Rev. B 1974, 10, 1319-1327. [CrossRef] 